\title{
Annotation and characterization of Babesia gibsoni apicoplast genome
}

\author{
Qin Liu ${ }^{1,2}$, Long Yu ${ }^{1,2}$, Fan Jiang ${ }^{3}$, Muxiao Li ${ }^{1,2}$, Xueyan Zhan ${ }^{1,2}$, Yuan Huang ${ }^{1,2}$, Sen Wang ${ }^{1,2}$, Xiaoyong Du ${ }^{3}$, \\ Lan $\mathrm{He}^{1,2,4^{*}}$ and Junlong Zhao $\mathrm{C}^{1,2,4}$
}

\begin{abstract}
Background: Babesia gibsoni is an apicomplexan parasite transmitted by ticks, which can infect canine species and cause babesiosis. The apicoplast is an organelle associated with isoprenoids metabolism, is widely present in apicomplexan parasites, except for Cryptosporidium. Available data indicate that the apicoplast is essential for the survival of apicomplexan parasites.
\end{abstract}

Methods: Here, the apicoplast genome of B. gibsoni was investigated by high-throughput genome sequencing, bioinformatics analysis, and conventional PCR.

Results: The apicoplast genome of B. gibsoni-Wuhan strain (B. gibsoni-WH) consists of a $28.4 \mathrm{~kb}$ circular molecule, with $\mathrm{A}+\mathrm{T}$ content of $86.33 \%$, similar to that of $B$. microti. Specifically, this genome encodes genes involved in maintenance of the apicoplast DNA, transcription, translation and maturation of organellar proteins, which contains 2 subunits of ribosomal RNAs, 17 ribosomal proteins, 1 EF-Tu elongation factor (tufA), 5 DNA-dependent RNA polymerase beta subunits, 2 Clp protease chaperones, 23 tRNA genes and 5 unknown open reading frames (hypothetical proteins). Phylogenetic analysis revealed high similarity of B. gibsoni apicoplast genome to that of B. orientalis and B. bovis.

Conclusions: To our knowledge, this is the first report of annotation and characterization of B. gibsoni-WH apicoplast genome. The results will facilitate the development of new anti-Babesia drug targets.

Keywords: Babesia gibsoni, Apicoplast genome, Sequencing, Annotation, Comparative analysis

\section{Background}

Babesia gibsoni, an obligate intraerythrocytic parasitic protozoan that can cause canine babesiosis [1-3], spreads widely around the world. Canine babesiosis caused by B. gibsoni may cause hyperacute, acute and more commonly chronic infection [3], with the clinical symptoms of fever, hemolytic anemia and even death $[4$, 5]. Babesia gibsoni is mainly transmitted by ticks but can also be transmitted by blood transfusion, dog bites and even transplacental route [6-9]. In an effort to improve the diagnosis and treatment of canine babesiosis, many

\footnotetext{
*Correspondence: helan@mail.hzau.edu.cn

1 State Key Laboratory of Agricultural Microbiology, College of Veterinary Medicine, Huazhong Agricultural University, Wuhan 430070, Hubei, China Full list of author information is available at the end of the article
}

research efforts have been devoted to pathogenicity, gene diversity and identification of new targets against the disease.

Apicomplexan parasites, except for Cryptosporidium, contain an apicoplast, which is a unique, essential organelle for the survival of these parasites [10]. The apicoplast has been reported to contain four membranes in apicomplexan parasites $[11,12]$ and results from a secondary endosymbiosis of eukaryotic algae, and that the red algae origin hypothesis is more likely than the green algae origin hypothesis [13, 14]. After the evolution from chloroplast into apicoplast, the genes encoding a variety of proteins, transfer RNAs (tRNAs) and ribosomal RNA (rRNA) are still present in apicomplexan parasites [15]. This endowed the apicoplast with a series of bacteria-like pathways to replicate and express its genome coupled

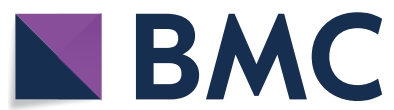

(c) The Author(s) 2020. This article is licensed under a Creative Commons Attribution 4.0 International License, which permits use, sharing, adaptation, distribution and reproduction in any medium or format, as long as you give appropriate credit to the original author(s) and the source, provide a link to the Creative Commons licence, and indicate if changes were made. The images or other third party material in this article are included in the article's Creative Commons licence, unless indicated otherwise in a credit line to the material. If material is not included in the article's Creative Commons licence and your intended use is not permitted by statutory regulation or exceeds the permitted use, you will need to obtain permission directly from the copyright holder. To view a copy of this licence, visit http://creativeco mmons.org/licenses/by/4.0/. The Creative Commons Public Domain Dedication waiver (http://creativecommons.org/publicdomain/ zero/1.0/) applies to the data made available in this article, unless otherwise stated in a credit line to the data. 
with an anabolic capacity for producing fatty acids, iron-sulphur cluster, haem and isoprenoid precursors [16-20]. A previous study has shown that interfering the apicoplast in laboratory conditions (such as interference with isoprenoid synthesis pathways) could cause parasite death, but the addition of relevant substitutes after interference does not affect parasite growth [21]. This confirms the importance of apicoplast for parasite survival, making it a hotspot in anti-parasitic drug design.

The apicoplast genomes of Babesia bovis, Babesia microti, Babesia orientalis and Toxoplasma gondii have been sequenced and characterized [12, 22-24]. However, little information is available about the apicoplast genome of B. gibsoni. Therefore, this study focused on the annotation and characterization of Babesia gibsoniWuhan strain (Babesia gibsoni-WH) apicoplast genome.

\section{Methods}

\section{Parasites and animal experiments}

Babesia gibsoni-WH was stored in liquid nitrogen in the State Key Laboratory of Agricultural Microbiology, Huazhong Agricultural University, China.

Two one-year-old beagles with health certificates were purchased from Anlu Laboratory Animal Center and confirmed to be Babesia-free by microscopic examination and PCR. After injection with $5 \mathrm{ml}$ of blood infected with $B$. gibsoni, the body temperature of the experimental beagles was observed daily and blood smears were prepared every second days to monitor the parasitemia. When parasitemia reached $20 \%$, blood was collected from the experimentally infected dogs for further research as described below.

\section{Purification of parasites}

The blood was collected from infected dogs into tubes containing EDTA- $\mathrm{K}_{2}$ solution, followed by storage at $4{ }^{\circ} \mathrm{C}$ for $2 \mathrm{~h}$ and centrifugation at $2000 \times \mathrm{rpm}$ at $4{ }^{\circ} \mathrm{C}$ for $10 \mathrm{~min}$. After removing the supernatant, a five-fold volume of hypotonic RBC lysis buffer $\left(\mathrm{Na}_{3} \mathrm{PO}_{4} / \mathrm{EDTA}, \mathrm{PH}\right.$ 7.6) was added to the pellets, followed by incubation at $37^{\circ} \mathrm{C}$ for $30 \mathrm{~min}$. Next, the lysate was filtered through a $2 \mu \mathrm{m}$ membrane (Whatman, Florham Park, USA) and the collected buffer was centrifuged at $12,000 \times g$ at $4{ }^{\circ} \mathrm{C}$ for $10 \mathrm{~min}$. Finally, the pellets were collected and stored at $-80^{\circ} \mathrm{C}$ until further use.

\section{DNA extraction}

Genomic DNA was extracted from purified parasites using the QIAamp DNA Mini Kit (Qiagen, Shanghai, China) according to the manufacturer's instructions. After passing the quality test, the genomic DNA was used for further analysis.

\section{Apicoplast genome sequencing}

The raw apicoplast sequence and the whole genome sequence (unpublished data) of B. gibsoni obtained from PacBio sequencing (Wuhan, China) were assembled using the CAP3 assembly program to obtain the raw sequence [25], which was used as reference to obtain highly conserved genes through BLAST alignment. Based on the conserved genes, primers were designed for conventional PCR amplification, followed by amplifying the sequence between two conserved genes (Additional file 1: Table S1). After several calibrations, the entire apicoplast genome was completely covered. The sequences were assembled again to obtain the final apicoplast genome sequence.

\section{Analysis and annotation}

The apicoplast genome of B. gibsoni was annotated by Artemis (https://www.sanger.ac.uk/resources/software/ artemis/) in combination with BLAST in NCBI (http:// blast.ncbi.nlm.nih.gov/Blast.cgi). The data was screened by Open Reading Frame Finder (ORFs) (https://www. ncbi.nlm.nih.gov/orffinder/) and GenMark (http://opal. biology.gatech.edu/GeneMark/index.html). Published protozoan apicoplast genomes were used as references to conceptually translate and annotate the putative code areas. The tRNA genes were predicted by tRNAscanSE 2.0 (http://lowelab.ucsc.edu/tRNAscan-SE/) with the following parameters: source "Mito/Chloroplast" and search mode "default". The rDNA sequences (SSU and $L S U$ ) were separately obtained by comparing the counterparts of B. bovis, B. microti and B. orientalis. Mis-annotations in the published apicoplast genomes were re-annotated. The maps of the B. gibsoni apicoplast genome were produced using online CGView software (http://stothard.afns.ualberta.ca/cgview_server/). The repeatability of rRNA genes was verified using the repeatmasker server (http://www.repeatmasker.org/cgibin/WEBRepeatMasker). The multiple genome alignments were generated by the software Mauve (http:// darlinglab.org/mauve/mauve.html). All of the above analysis results were corrected manually on a gene-bygene basis as needed. The reference genomes used in this study included NC_011395 (B. bovis), KT428643.1 (B. orientalis), KX881914.1 (Babesia sp. Xinjiang), LK028575 (B. microti), NC_007758 (T. parva), X95275 (IRA) and X95276 (IRB) (P. falciparum), U87145 (T. gondii), NC_014345.1 (Alveolata sp. CCMP3155). The phylogenetic tree of the rRNA genes was constructed using MEGA 7.0 with the Maximum Likelihood method (https ://www.megasoftware.net/). The functional domains and transmembrane domain were separately predicted by using the software Pfam (http://pfam.sanger.ac.uk/) [26] and TMpred (http://www.ch.embnet.org/software/ TMPRED_form.html). 


\section{Results and discussion}

\section{Characteristics of apicoplast genome sequence of $B$. gibsoni}

The available literature has shown limited genetic information of B. gibsoni, and the apicoplast genome sequence remains unavailable. Herein, we sequenced, assembled, annotated and characterized the apicoplast genome of $B$. gibsoni. The raw apicoplast genome sequence of B. gibsoni obtained from high throughput genome sequencing (data unpublished) was shown to have a circular form with a full length of $46 \mathrm{~kb}$, which is bigger than that of any other reported Babesia apicoplast genome [22, 23, 27-29]. To further verify the sequence, we adopted a primer-walking approach to test the B. gibsoni genomic DNA by designing a series of specific primers based on the amplicons covering the whole apicoplast genome (Additional file 1: Table S1, Additional file 2: Figure S1). According to the principle of primer design, the sequences of conserved genes were amplified first, followed by amplifying the sequences between two conserved genes until the entire apicoplast genome was completely covered. Data analysis indicated that the assembled circular molecule has two completely repeating fragments (1-17,648 and 28,333$45,999)$ with a size of $17.6 \mathrm{~kb}$. The apicoplast genome of $B$. gibsoni was shown to be a circular DNA of $28.4 \mathrm{~kb}$ with $\mathrm{A}+\mathrm{T}$ content of $86.33 \%$, which is similar to that of B. microti (28.7 kb, A + T\%=86\%) (Table 1) [23].

The Babesia gibsoni apicoplast genome contains 2 rRNAs, 23 tRNAs and 30 protein-coding genes (Table 2). Specifically, the 2 rRNA genes are composed of $S S U$ and $L S U$ genes. The 30 protein-coding genes comprise an EF-Tu elongation factor (tufA) gene, 2 Clp protease chaperone genes $(C l p C 1, C l p C 2), 5$ DNAdependent RNA polymerase genes (RpoB, RpoB2, $R p o C 1, R p o C 2 a, R p o C 2 b), 17$ ribosomal proteins (rpland rps-) and 5 hypothetical proteins (hp 1-5), with all of them in the same direction (Fig. 1, Table 2). The initiation codons are almost all AUG for the $30 \mathrm{CDSs}$ (codon sequences), excluding UAU for RpoB. There is an A-rich region in front of these CDS, which may play a significant role in the renewal of the ribosome population. UAA (26 of the $30 \mathrm{CDSs}$ ) and UGA (4 of the 30 CDSs) serve as termination codons for the CDSs of $B$. gibsoni apicoplast genome. The $s u f B$ gene of the protein involved in the iron-sulfur cluster assembly in the apicoplast genome of P. falciparum, which is absent in the apicoplast genome of $B$. gibsoni [12]. Complete annotation of the plastid genome indicated that B. gibsoni

Table 1 Characterization of Babesia gibsoni apicoplast genome and comparison with related species

\begin{tabular}{|c|c|c|c|c|c|c|c|c|}
\hline Species & Babesia gibsoni & Babesia microti & $\begin{array}{l}\text { Babesia } \\
\text { orientalis }\end{array}$ & $\begin{array}{l}\text { Babesia bovis } \\
\text { T2Bo }\end{array}$ & $\begin{array}{l}\text { Babesia sp. } \\
\text { Xinjiang }\end{array}$ & $\begin{array}{l}\text { Theileria parva } \\
\text { Muguga }\end{array}$ & $\begin{array}{l}\text { Plasmodium } \\
\text { falciparum C10 }\end{array}$ & $\begin{array}{l}\text { Toxoplasma } \\
\text { gondii } \mathrm{RH}\end{array}$ \\
\hline Size (bp) & 28,386 & 28,657 & 33,200 & 33,351 & 30,729 & 39,579 & 34,682 & 34,996 \\
\hline $\mathrm{A}+\mathrm{T}(\%)$ & 86.33 & 86 & 78.9 & 78.2 & 81 & 80.5 & 86.9 & 78.6 \\
\hline Inverted repeat & - & - & - & - & - & - & + & + \\
\hline sufB & - & - & - & - & - & - & + & + \\
\hline$r p / 23$ & - & - & - & - & - & - & + & - \\
\hline tRNA & 23 & 24 & 24 & 24 & 25 & 24 & 34 & 33 \\
\hline GenBank ID & MN481613 & LK028575 & KT428643.1 & NC_011395 & KX881914.1 & NC_007758 & $\begin{array}{r}\times 95275 \\
\times 95276\end{array}$ & U87145 \\
\hline
\end{tabular}

Note: "Inverted repeat" indicates the information of the two genetic structures of LSU and SSU

Table 2 Gene contents of the Babesia gibsoni apicoplast genome

\begin{tabular}{|c|c|}
\hline Class & Gene \\
\hline Ribosomal RNA & LSU, SSU \\
\hline Transfer RNA ${ }^{a}$ & 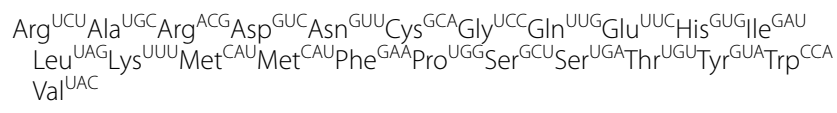 \\
\hline \multirow[t]{2}{*}{ Ribosomal proteins } & $\operatorname{rps} 2,3,4,5,7,8,11,12,17,19$ \\
\hline & $r p / 2,4,5,6,14,16,36$ \\
\hline RNA polymerase & $r p o \mathrm{~B}, r p o \mathrm{~B} 2, r p o \mathrm{C} 1, r p o \mathrm{C} 2 \mathrm{a}, r p o \mathrm{C} 2 \mathrm{~b}$ \\
\hline Other proteins & ClpC1, ClpC2, tufA \\
\hline Unassigned ORFs & 5 ORFs (hyp 1-5) \\
\hline
\end{tabular}

a Three-letter amino acid code and anti-codon 


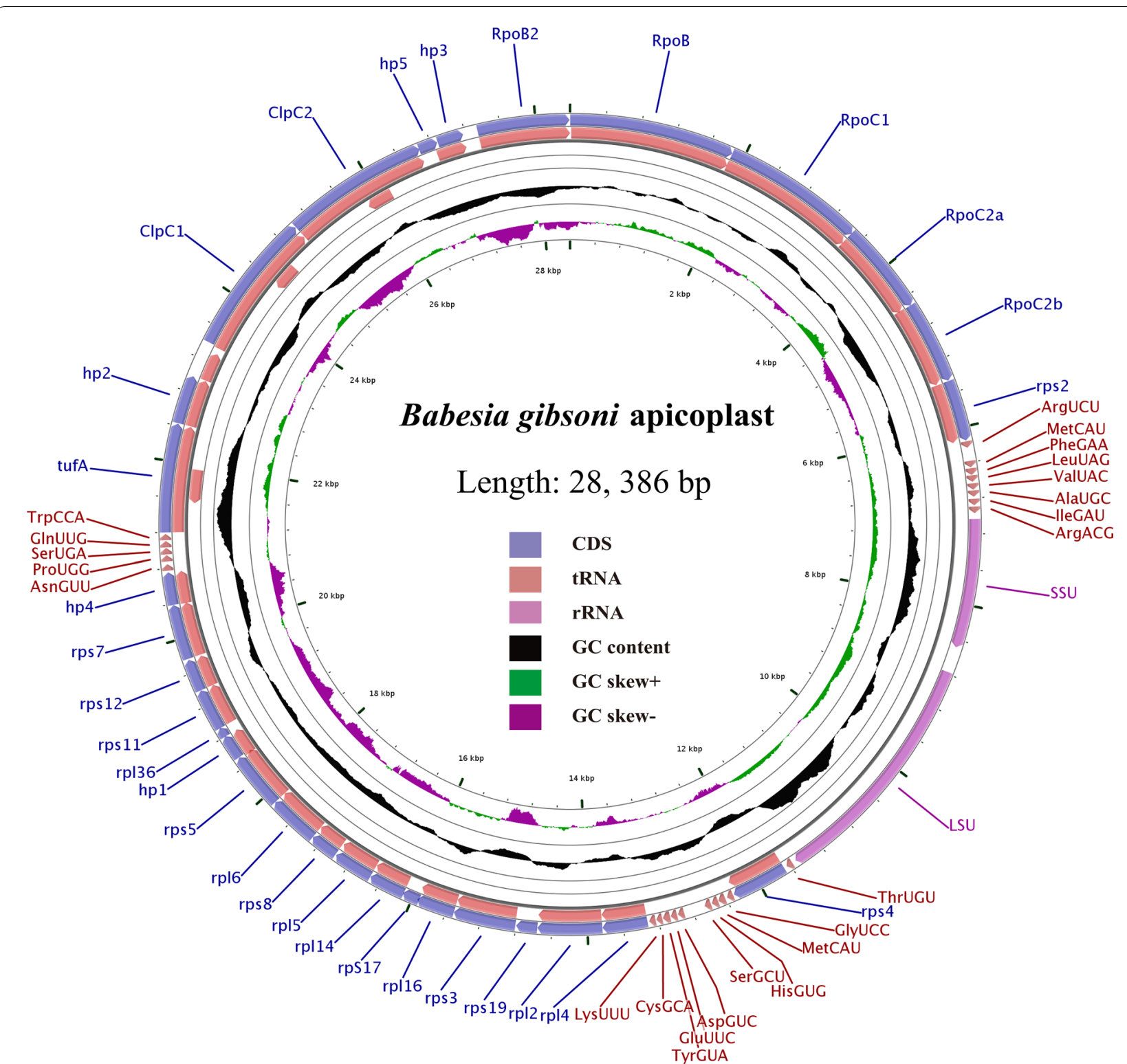

Fig. 1 Circular map of the apicoplast genome of Babesia gibsoni. The map was designed using CGview. Different colors: coding sequence (CDS), tRNA, rRNA, GC content, GC skew and base coordinates. Hp1-5 represent five hypothetical protein-encoding genes found in the apicoplast genome of $B$. gibsoni

is more similar to Babesia spp. than to Toxoplasma or Plasmodium (Additional file 3: Figure S2). Additionally, almost all genes present in the apicoplast genomes of $B$. orientalis and $B$. microti were found in the apicoplast genome of B. gibsoni.

It has been reported that there are basically 24 tRNAs in Babesia spp. and more than 30 tRNAs in Plasmodium and Toxoplasma of the apicomplexan parasites (Table 1). The tRNAscan-SE analysis identified 23 tRNAs in B. gibsoni, which was less than that in other Babesia spp. Excluding one intron-containing tRNA (Leu-UAA), all the other tRNAs were the same as those in the apicoplast genomes of $B$. gibsoni and B. orientalis (Additional file 1: Table S2). Previous reports have shown that the apicoplast is derived from a secondary endosymbiont of eukaryotic algae, and the genomic information also indicates that the apicoplast genome conforms to the characteristics of the prokaryotic genome [10]. In prokaryotes, tRNA-fMet is an initiation tRNA. Interestingly, Met and iMet exist in both B. microti and B. orientalis, while there is only tRNA-Met in B. gibsoni.

Analysis revealed conspicuous similarities of rRNAs and ribosomal proteins from the apicoplast genome of 
B. gibsoni with those of other apicomplexan parasites. The apicoplast genome encodes proteins of large ribosomal subunits and small ribosomal subunits, containing 7 rpl proteins and 10 rps proteins, respectively. Genomewide analysis of $B$. gibsoni suggests that the genes of the remaining ribosomal proteins may be transferred to the nuclear genome and then targeted to the apicoplast for function (unpublished data). This finding is also consistent with the observations in other apicomplexan parasites [30-32]. Highly conserved 16S-like and 23S-like rRNA genes were predicted in the apicoplast genome of $B$. gibsoni, while $5 S$ rRNA encoding the $r f f$ gene was absent in the apicoplast genomes of B. gibsoni and other apicomplexan parasites [22, 23, 33]. This implies that the apicoplast ribosomes of $B$. gibsoni are not regulated by $5 S$ rRNA, or the $r r f$ gene sequence is different from that of the known $r r f$ genes, or import $5 S$ rRNA from the cytoplasm [34, 35]. The Chromera chloroplast genome was reported to express the $r f f$ gene, while no $r r f$ gene was identified in the apicoplast genomes of all apicomplexan parasites, except in the nuclear genomes [23].

In addition to the genes for tRNAs and rRNAs, the apicoplast genome B. gibsoni encodes genes for 2 copies of ClpC chaperone, 5 subunits of RNA polymerase, an EF-Tu elongation factor and 5 hypothetical coding sequences (hp 1-5). Except for the hypothetical coding sequences, the other genes shared a high homology in the apicoplast genomes of the apicomplexan parasite. The encoded putative proteins (hp 1-5) showed no significant homology to any of the proteins in the existing database and did not contain any identifiable functional domains. Compared with other apicomplexan parasite genomes, the results suggest the existence of hypothetical proteins with unknown functions and the different sequences in the same genomic regions. The expression of these CDS remains to be determined.

\section{Characteristics of gene clusters in the apicoplast genome of B. gibsoni}

The synteny of the apicoplast genome of $B$. gibsoni with those of other apicomplexan parasites was investigated by comparing the genetic structure of four clusters in their apicoplast genomes and the chloroplast genomes of Chromera algae [36].

Cluster 1 contains an EF-Tu elongation factor (tufA) and genes encoding ribosomal proteins (Fig. 2). In this Cluster, a relatively high homology was shown in the chloroplast genome of Chromera algae and the apicoplast genome of apicomplexan parasites. The rpl23 gene is absent in the apicoplast genome of $B$. gibsoni, which

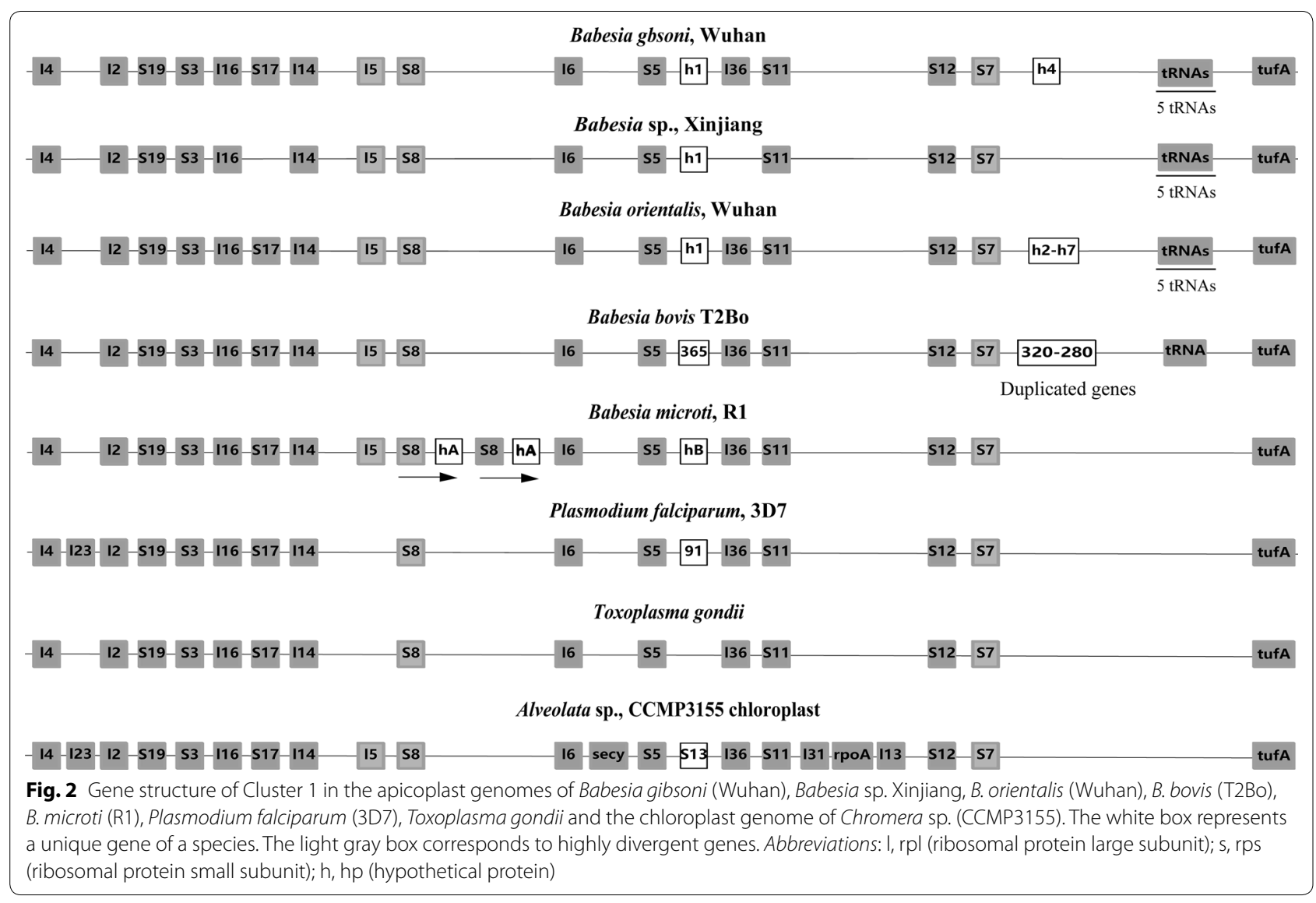


is similar to the gene structure of Babesia sp. Xinjiang, B. bovis and other Babesia spp. The rpl23 gene is located between the $r p l 2$ gene and the rpl4 gene, which was only identified in Chromera and Plasmodium species, but this gene has been lost in the apicoplast genome during evolution of apicomplexan parasites. In Cluster 1, the rps 13 gene was only present between rps 5 and rpl36 in Chromera sp. and absent in all apicomplexan parasites. As shown in Fig. 2, this region was replaced by a gene with unknown function, or lacked CDS at most apicomplexan parasites, like in T. gondii.

Cluster 2 is mainly composed of $C l p C$ chaperones. In apicomplexan parasites, the $C l p C$ gene contains transmembrane domains (TM) and putative protein domains on both sides (Fig. 3). Similar to B. microti and B. bovis, the $C l p C$ gene of $B$. gibsoni is also composed of two copies containing the AAA_2 ATPase domains (Additional file 4: Figure S3). Unlike Babesia spp., there is only one copy containing the enzyme domain for T. gondii and P. falciparum. In this cluster, the $C l p C$ genes of $T$. gondii and $P$. falciparum are surrounded by tRNAs, which is not the case for B. gibsoni and B. orientalis. There is an rpl11 ribosomal gene in the chloroplast genome of Chromera sp., which was absent in the apicoplast genomes of all the other known apicomplexan parasites excluding $T$. gondii (Figs. 3, 4). This suggests that the rpl11 protein may be non-essential or contains one or more rpl11-like proteins or that this gene is encoded in the nuclear genome and then transferred to the apicoplast through the relevant pathway [30, 37].

Cluster 3 contains RNA polymerase genes (RpoB, $R p o \mathrm{~B} 2, R p o \mathrm{C} 1, R p o \mathrm{C} 2 \mathrm{a}, R p o \mathrm{C} 2 \mathrm{~b})$ and the rps 2 gene

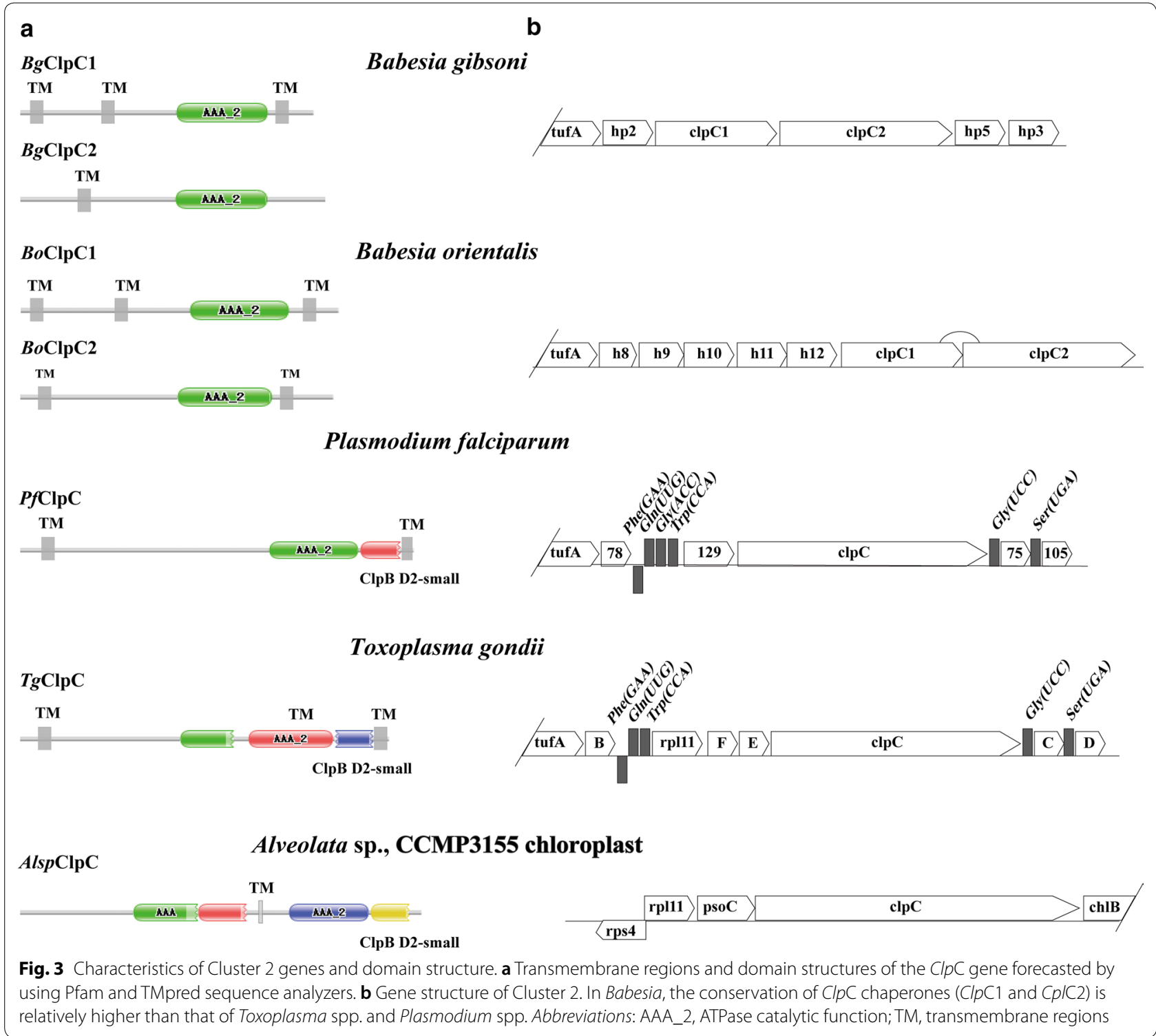




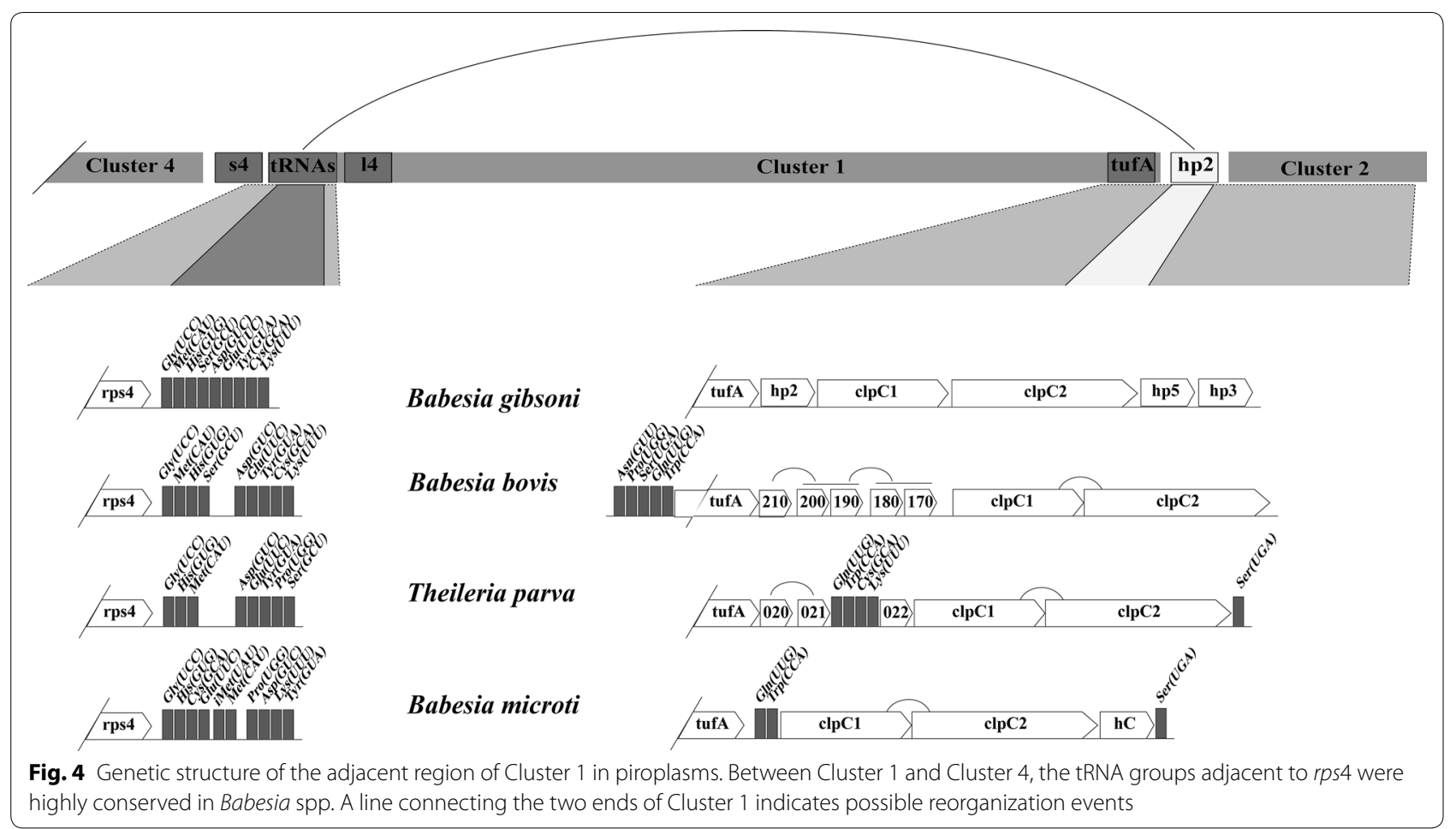

encoding the S2 ribosomal protein (Fig. 1). In algal chloroplast genomes, the alpha subunit of RNA polymerase (RpoA) gene is present in Cluster 1, whereas the RpoA gene is absent in the plastid genomes of B. gibsoni and other apicomplexan parasites, which was finally found to be encoded by the nuclear genome (Fig. 2). In the present study, 5 RNA polymerase genes were identified in B. gibsoni, one more than the number in B. orientalis or $B$. microti. However, the gene content and location of Cluster 3 are basically the same as those in B. gibsoni, B. microti and T. parva, indicating that it is a conserved region during evolution of Piroplasmida.

Cluster 4 contains rDNA genes ( $L S U$ and $S S U$ ). The $S S U$ and $L S U$ genes are all single copies in Babesia spp. except for $B$. bovis, with the same transcription direction for all of them. However, the $S S U$ and $L S U$ are a set of multi-copy genes with opposite transcription direction in the apicoplast genomes of $T$. gondii and P. falciparum (Fig. 5). Meanwhile, the gene content and gene sequence in the cluster vary among species. In $P$. falciparum and T. gondii, the SSU and LSU genes are in the opposite direction with multiple copies; in B. gibsoni and T. parva, there is no tRNA between SSU and $L S U$ genes; in B. bovis, there are two copies of the SSU gene and 2 Thr (UGU) tRNAs (Fig. 5). The formation of this genetic structure may be related to the occurrence of mutations during evolution of B. bovis [10, 14, 30, 38].
The genetic structure of each cluster and the region between clusters is different. Cluster 4 and Cluster 1 showed high similarity in regions, in contrast to the obvious difference between Cluster 1 and Cluster 2 (Fig. 4). In Babesia spp., the region between Cluster 1 and Cluster 2 is composed of multiple hypothetical protein regions, while in $B$. microti, the hypothetical protein was substituted by two tRNA genes for Gln (UUG) and Trp (CCA). Interestingly, the two coding regions described above are present in T. parva, along with two other tRNAs. These data suggest a high mutation rate in the region between Cluster 1 and Cluster 2 during evolution of the species, which can be speculated as a hotspot for recombination, and the region near Cluster 1 may have undergone significant recombination events during the evolution of Piroplasmida (Fig. 4). As mentioned above, the gene sequence of $r p l 11-C l p C$ is highly conserved in $T$. gondii and Chromera, but the rpl11 gene is absent in the apicoplast genomes of parasites within the Class Aconoidasida (which includes Piroplasmida and Haemosporida). Moreover, previous research has shown the occurrence of the rearrangement of the tRNA adjacent to the $C l p C$ gene, so it was speculated that the deletion of the $r p 111$ gene might be related to the rearrangement of tRNA (Figs. 3, 4). The two stages, i.e. (i) from the free-living protoapicomplexan to the first apicomplexan, and (ii) from the ancestor of the piroplasm and coccidian to 


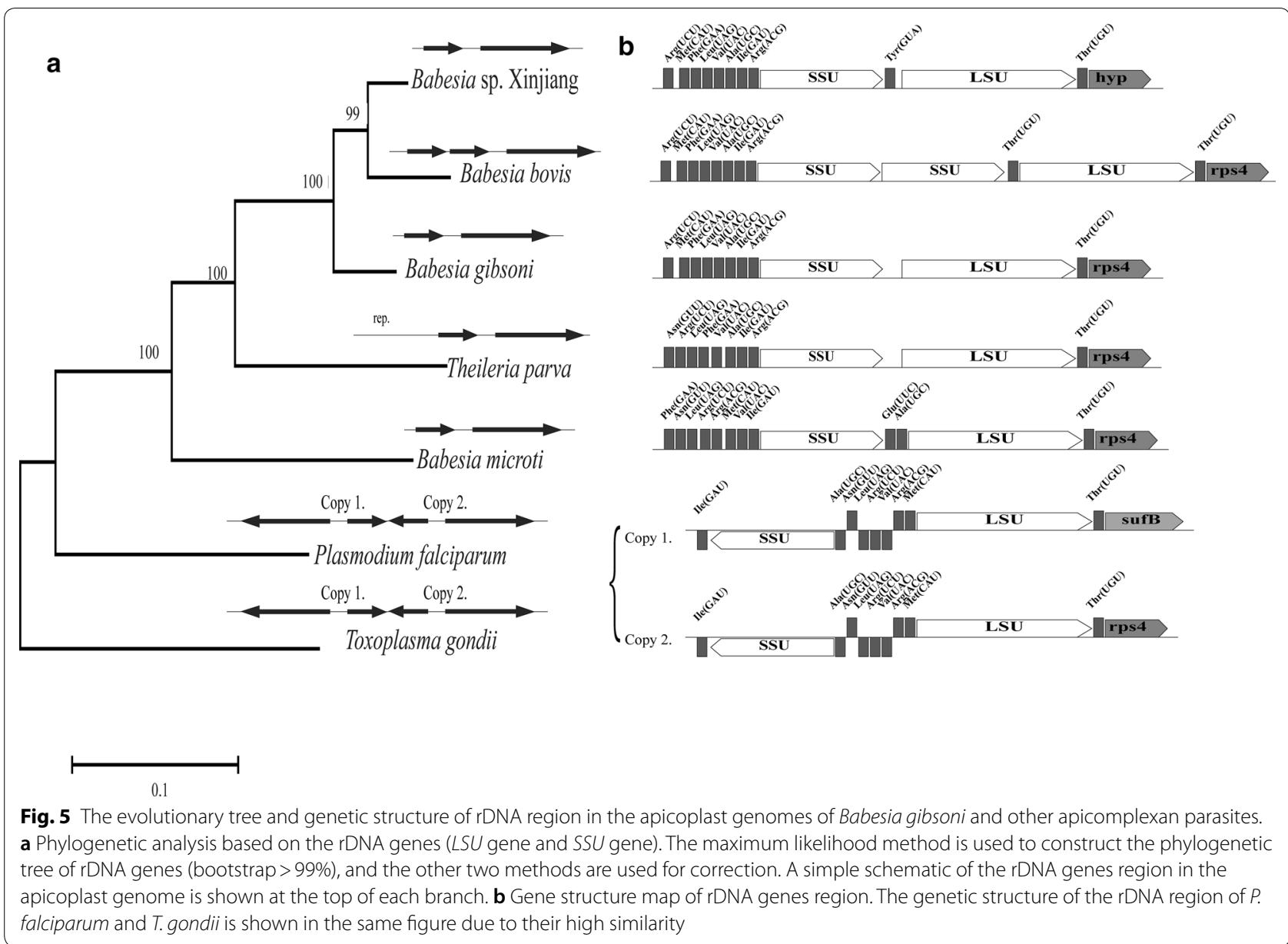

the first hematozoan, are shown to be important in the evolution of the parasite, due to the occurrence of gene deletion events and gene rearrangements in these two stages [38]. Therefore, we speculate that only a few simple genes were maintained in the apicoplast genome from these two stages of evolution, with some of them being transferred to the nuclear genome and then targeted to the apicoplast for function.

\section{Conclusions}

In this study, we sequenced, assembled and annotated the apicoplast genome of $B$. gibsoni. The apicoplast genome of $B$. gibsoni is a $28.4 \mathrm{~kb}$ circular genome, with a high similarity in genetic structure and characteristics to those of other apicomplexan parasites (e.g. Babesia spp., Plasmodium spp., Toxoplasma spp.). Babesia gibsoni apicoplast genes have been gradually lost or transferred to the nuclear genome during evolution. Currently, we are trying to identify the proteins encoded by the nuclear genome and targeted to the apicoplast to improve our understanding of its metabolic pathways. This study provided a genetic basis for screening novel drug targets against babesiosis.

\section{Supplementary information}

Supplementary information accompanies this paper at https://doi. org/10.1186/s13071-020-04065-7.

Additional file 1: Table S1. PCR primers used in sequencing the apicoplast genome of Babesia gibsoni. Table S2. Comparison of tRNA in the populations of P. falciparum, T. gondii, B. microti, B. gibsoni and B. orientalis.

Additional file 2: Figure $S 1$. PCR results of amplified fragments of the apicoplast genome from Babesia gibsoni gDNA. Lane M: Marker; Lanes 1, 2: 35\#; Lanes 3, 4: 37\#; Lane 5: 38\#; Lanes 6, 7: 31\#; Lanes 8, 9: 34\#; Lanes 10, 11: 32\#; Lanes 12, 13: JTC-2; Lane 14, 15: JTC-3; Lane 16: TufA; Lanes 17, 18: 42\#; Lanes 19, 20: 41\#; Lanes 21, 22: 44\#; Lanes 23, 24: 47\#.

Additional file 3: Figure S2. Molecular phylogenetic analysis by maximum likelihood method. Evolutionary analyses were conducted in MEGA7. The genes analyzed by the evolutionary tree are present in all of these species (rpl4, rp/2, rps 19, rps3, rp/16, rp/14, rps8, rp/6, rps5, rp/36, rps11, rps12, rps7, TufA).

Additional file 4: Figure S3. Domain structure of the ClpC chaperone of piroplasma. Two PfamA domains were found in ClpC proteins of Babesia spp.: AAA_2 (ATPase catalytic function). 


\section{Abbreviations}

tufA: 1 EF-Tu elongation factor; tRNA: Transfer RNA; rRNA: Ribosomal RNA; WH: Wuhan strain; hp: Hypothetical protein; IPP: Isopentene pyrophosphate pathway; LSU: Large-subunit ribosomal; SSU: Small-subunit ribosomal; rpl: Ribosomal protein large subunit; rps: Ribosomal protein small subunit; hp: Hypothetical protein.

\section{Acknowledgements}

Special thanks to Xiaoyong Du, Hubei Key Laboratory of Agricultural Bioinformatics, College of Informatics, Huazhong Agricultural University, China, for his contribution to data assembly and analysis.

\section{Authors' contributions}

$\mathrm{QL}, \mathrm{LH}$ and JZ designed the study and QL drafted the manuscript. QL performed the experiments with help from $L Y, X Z, S W, Y Z, X A$ and TA. QL analyzed the sequencing results and generated the data with help from FJ, YH, XL and XW. All authors read and approved the final manuscript.

\section{Funding}

The work was supported by the National Key Research and Development Program of China (2017YFD0500402 and 2017YFD0501201), the National Natural Science Foundation of China (31772729) and the National Key Basic Research Program (973 Program) of China (2015CB150302)

\section{Availability of data and materials}

Data supporting the conclusions of this article are included within the article and its additional files. The apicoplast genome sequence of Babesia gibsoni generated during this study was submitted to the NCBI GenBank database under the accession number MN481613. The datasets used and analyzed in this study can be obtained from the corresponding author upon reasonable request.

\section{Ethics approval and consent to participate}

The feeding conditions and environment of all experimental animals comply with and strictly per the stipulated rules for the Regulation of the Administration of Affairs Concerning Experimental Animals of PR China, Laboratory Animals Research Centre of Hubei Province and the Ethics Committee of Huazhong Agricultural University (license number: HZAUDO-2017-005). Each experimental animal was carefully treated during the experiment so that the damage to the experimental animals could be minimized.

\section{Consent for publication}

Not applicable.

\section{Competing interests}

The authors declare that they have no competing interests.

\section{Author details}

${ }^{1}$ State Key Laboratory of Agricultural Microbiology, College of Veterinary Medicine, Huazhong Agricultural University, Wuhan 430070, Hubei, China.

${ }^{2}$ Key Laboratory of Preventive Veterinary Medicine in Hubei Province, Wuhan 430070, Hubei, China. ${ }^{3}$ Hubei Key Laboratory of Agricultural Bioinformatics, College of Informatics, Huazhong Agricultural University, Wuhan 430070, Hubei, China. ${ }^{4}$ Key Laboratory of Development of Veterinary Diagnostic Products, Ministry of Agriculture of the People's Republic of China Wuhan 430070, Hubei, China.

Received: 31 October 2019 Accepted: 9 April 2020

Published online: 21 April 2020

\section{References}

1. Singh MN, Raina OK, Sankar M, Rialch A, Tigga MN, Kumar GR, et al. Molecular detection and genetic diversity of Babesia gibsoni in dogs in India. Infect Genet Evol. 2016;41:100-6.

2. Kjemtrup AM, Kocan AA, Whitworth L, Meinkoth J, Birkenheuer AJ, Cummings J, et al. There are at least three genetically distinct small piroplasms from dogs. Int J Parasitol. 2000:30:1501-5.

3. Irwin PJ. Canine babesiosis. Vet Clin North Am Small Anim Pract. 2010:40:1141-56.
4. Casapulla R, Baldi L, Avallone V Sannino R, Pazzanese L Mizzoni V. Canine piroplasmosis due to Babesia gibsoni: clinical and morphological aspects. Vet Rec. 1998:142:168-9.

5. Wozniak EJ, Barr BC, Thomford JW, Yamane I, McDonough SP, Moore PF, et al. Clinical, anatomic, and immunopathologic characterization of Babesia gibsoni infection in the domestic dog (Canis familiaris). J Parasitol. 1997:83:692-9.

6. Baneth G, Breitschwerdt EB, Hegarty BC, Pappalardo B, Ryan J. A survey of tick-borne bacteria and protozoa in naturally exposed dogs from Israel. Vet Parasitol. 1998;74:133-42.

7. Stegeman JR, Birkenheuer AJ, Kruger JM, Breitschwerdt EB. Transfusionassociated Babesia gibsoni infection in a dog. J Am Vet Med Assoc. 2003;222(959-63):52.

8. Birkenheuer AJ, Correa MT, Levy MG, Breitschwerdt EB. Geographic distribution of babesiosis among dogs in the United States and association with dog bites: 150 cases (2000-2003). J Am Vet Med Assoc. 2005;227:942-7.

9. Fukumoto S, Suzuki H, Igarashi I, Xuan X. Fatal experimental transplacental Babesia gibsoni infections in dogs. Int J Parasitol. 2005;35:1031-5.

10. Arisue N, Hashimoto T. Phylogeny and evolution of apicoplasts and apicomplexan parasites. Parasitol Int. 2015;64:254-9.

11. Howe CJ. Plastid origin of an extrachromosomal DNA molecule from Plasmodium, the causative agent of malaria. J Theor Biol. 1992;158:199-205.

12. Wilson RJ, Denny PW, Preiser PR, Rangachari K, Roberts K, Roy A, et al. Complete gene map of the plastid-like DNA of the malaria parasite Plasmodium falciparum. J Mol Biol. 1996:261:155-72.

13. Foth BJ, MCFadden GI. The apicoplast: a plastid in Plasmodium falciparum and other Apicomplexan parasites. Int Rev Cytol. 2003;224:57-110.

14. Marechal E, Cesbron-Delauw MF. The apicoplast: a new member of the plastid family. Trends Plant Sci. 2001;6:200-5.

15. Gardner MJ, Williamson DH, Wilson RJM. A circular DNA in malaria marasites encodes an RNA polymerase like that of prokaryotes and chloroplasts. Mol Biochem Parasitol. 1991;44:115-23.

16. McFadden Gl. The apicoplast. Protoplasma. 2011;248:641-50.

17. Gardner MJ, Hall N, Fung E, White O, Berriman M, Hyman RW, et al. Genome sequence of the human malaria parasite Plasmodium falciparum. Nature. 2002:419:498-511.

18. Roos DS, Crawford MJ, Donald RGK, Fraunholz M, Harb OS, He CY, et al. Mining the Plasmodium genome database to define organellar function: what does the apicoplast do? Philos Trans R Soc Lond B Biol Sci. 2002:357:35-46.

19. Sato S, Clough B, Coates L, Wilson RJM. Enzymes for heme biosynthesis are found in both the mitochondrion and plastid of the malaria parasite Plasmodium falciparum. Protist. 2004;155:117-25.

20. Ralph SA. Strange organelles - Plasmodium mitochondria lack a pyruvate dehydrogenase complex. Mol Microbiol. 2005;55:1-4.

21. Yeh E, DeRisi JL. Chemical rescue of malaria parasites lacking an apicoplast defines organelle function in blood-stage Plasmodium falciparum. PLoS Biol. 2011;9:e1001138.

22. Huang Y, He L, Hu J, He P, He J, Yu L, et al. Characterization and annotation of Babesia orientalis apicoplast genome. Parasit Vectors. 2015;8:543.

23. Garg A, Stein A, Zhao W, Dwivedi A, Frutos R, Cornillot E, et al. Sequence and annotation of the apicoplast genome of the human pathogen Babesia microti. PLoS One. 2014:9:e107939.

24. Lau AO, McElwain TF, Brayton KA, Knowles DP, Roalson EH. Babesia bovis: a comprehensive phylogenetic analysis of plastid-encoded genes supports green algal origin of apicoplasts. Exp Parasitol. 2009;123:236-43.

25. Huang X, Madan A. CAP3: a DNA sequence assembly program. Genome Res. 1999:9:868-77.

26. El-Gebali S, Mistry J, Bateman A, Eddy SR, Luciani A, Potter SC, et al. The Pfam protein families database in 2019. Nucleic Acids Res. 2019;47:D427-32

27. Wang X, Wang J, Liu J, Liu A, He X, Xu J, et al. Comparative analysis of apicoplast genomes of Babesia infective to small ruminants in China. Parasit Vectors. 2019;12:312.

28. Wang T, Guan G, Korhonen PK, Koehler AV, Hall RS, Young ND, et al. The apicoplast genomes of two taxonomic units of Babesia from sheep. Vet Parasitol. 2017:233:123-8.

29. Virji AZ, Thekkiniath J, Ma W, Lawres L, Knight J, Swei A, et al. Insights into the evolution and drug susceptibility of Babesia duncani from the 
sequence of its mitochondrial and apicoplast genomes. Int J Parasitol. 2019:49:105-13.

30. Martin W, Herrmann RG. Gene transfer from organelles to the nucleus: how much, what happens, and why? Plant Physiol. 1998;1 18:9-17.

31. Foth BJ, Ralph SA, Tonkin CJ, Struck NS, Fraunholz M, Roos DS, et al. Dissecting apicoplast targeting in the malaria parasite Plasmodium falciparum. Science. 2003;299:705-8.

32. Chakraborty A. Understanding the biology of the Plasmodium falciparum apicoplast; an excellent target for antimalarial drug development. Life Sci. 2016;158:104-10

33. Arisue N, Hashimoto T, Mitsui H, Palacpac NM, Kaneko A, Kawai S, et al. The Plasmodium apicoplast genome: conserved structure and close relationship of P. ovale to rodent malaria parasites. Mol Biol Evol. 2012;29:2095-9.

34. Magalhaes PJ, Andreu AL, Schon EA. Evidence for the presence of $5 S \mathrm{rRNA}$ in mammalian mitochondria. Mol Biol Cell. 1998;9:2375-82.
35. Yoshionari S, Koike T, Yokogawa T, Nishikawa K, Ueda T, Miura K, et al. Existence of nuclear-encoded 5S-rRNA in bovine mitochondria. FEBS Lett. 1994;338:137-42.

36. Janouskovec J, Horak A, Obornik M, Lukes J, Keeling PJ. A common red algal origin of the apicomplexan, dinoflagellate, and heterokont plastids. Proc Natl Acad Sci USA. 2010;107:10949-54.

37. McFadden GI, Yeh E. The apicoplast: now you see it, now you don't. Int Parasitol. 2017;47:137-44.

38. Otto TD, Gilabert A, Crellen T, Bohme U, Arnathau C, Sanders M, et al. Genomes of all known members of a Plasmodium subgenus reveal paths to virulent human malaria. Nat Microbiol. 2018;3:687-97.

\section{Publisher's Note}

Springer Nature remains neutral with regard to jurisdictional claims in published maps and institutional affiliations.
Ready to submit your research? Choose BMC and benefit from:

- fast, convenient online submission

- thorough peer review by experienced researchers in your field

- rapid publication on acceptance

- support for research data, including large and complex data types

- gold Open Access which fosters wider collaboration and increased citations

- maximum visibility for your research: over 100M website views per year

At BMC, research is always in progress.

Learn more biomedcentral.com/submissions 